\title{
A2L low GWP HFO based refrigerant solutions in heat pump applications to drive energy effi- ciency, safety, and sustainability even in build- ing restoration
}

\author{
Hans-Dieter Küpper ${ }^{1}$, Alessandro Pianetti ${ }^{2, *}$, and Samer Saab $^{3}$ \\ ${ }^{1}$ Chemours Deutschland GmbH, Neu-Isenburg, Germany \\ ${ }^{2}$ Chemours Italy srl, Agrate Brianza (MB), Italy \\ ${ }^{3}$ Chemours France SAS, Villers Saint Paul, Rieux, France
}

\begin{abstract}
Driven by energy efficiency requirements and legal restrictions like F-Gas Regulation Heat Pump OEM supplier are looking for alternative refrigerant solutions. HFO based low GWP refrigerants can help increasing the system efficiency, expanding the operating temperature range while reducing $\mathrm{CO} 2$ emissions. For building restoration in particular, high flow temperatures (for existing hydronic heating system) are essential for convenient and cost- and energy-efficient replacements of fossil fuel boilers. A2L classified refrigerants provide extended application range at highest safety level versus A3 classified refrigerants, but R-32 still carries a Global Warming Potential (GWP) of 675 making it a transitional solution. This paper compares different relevant parameters and points out the advantages provided by HFO A2L low GWP refrigerants (like R-454B and R-454C) for a wide capacity range of air to water and brine to water heat pumps. A special focus is put on the application of building restoration. Key words: HFO, HFO blend, COP, Energy Efficiency, A2L, A3, performance, safety, sustainability, operating range, heat pump, building restoration
\end{abstract}

\section{INTRODUCTION}

As part of the European Green Deal, the European Commission proposed in September 2020 to raise the 2030 greenhouse gas emission reduction target, including emissions and removals, to at least $55 \%$ compared to 1990. Considering that almost $50 \%$ of EU final energy consumption is used for heating and cooling, of which $80 \%$ is used in buildings. Therefore, the Energy Performance of Buildings Directive (EPBD) (Directive 2018/844) encourages creating a roadmap for the energy renovation of existing buildings and defines a strategy which includes the heating and cooling for reaching Nearly Zero-Energy Buildings.

${ }^{(*)}$ Corresponding author : alessandro.pianetti@,chemours.com 
Several studies have positioned heat pumps as a major enabler for energy consumption reduction in new buildings:

Simon Harvey: "Industrial HPs have an important role to play!" in: The role of heat pumps for decarbonization of industrial processes, $12^{\text {th }}$ IEA Heat Pump Conference 2017, Rotterdam [8]

European Commission: "Identifying/estimating current heating and cooling supply by technology: (among others) - heat pumps, ..." in: Annexes to the Commission Recommendation on the content of the comprehensive assessment of the potential for efficient heating and cooling under Article 14 of Directive 2012/27/EU, C(2019) 6625 final, ANNEXES 1 to 7, Brussels, 25.9.2019 [3]

European Commission: “...the integration of renewable and surplus energy into buildings. ... photovoltaic solar panels on the roofs, thermal storage and heat pumps" in: Communication from the Commission to the European Economic and Social Committee and the Committee of the Regions, A Renovation Wave for Europe - greening our buildings, creating jobs, improving lives, COM(2020) 662 final, Brussels, 14.10.2020 [4]

Thomas Nowak (EHPA): “100 \% Renewable Energy with Heat Pumps is feasible today." in: Heat Pumps; Integrating technologies to decarbonize heating and cooling, European Copper Institute, Autumn 2018 [12]

When it comes to Heat Pumps, the refrigerant choice has an impact on energy consumption. While the F-gas Regulation (Regulation (EU) No 517/2014) and the Kigali amendment to the Montreal Protocol drive the adoption of new refrigerants from the Heat Pump manufacturers with the objective of reducing their Global Warming Potential, the energy efficiency still plays the major role in the selection of refrigerants and Heat Pumps system design.

\section{SPECIAL NEEDS FOR BUILDING RENOVATION}

\subsection{Heating Capacity Needs}

For a typical Central-European new building, there is a heating system requirement for a relative heating capacity of $35 \mathrm{~W} / \mathrm{m}^{2}$, while for existing buildings - depending on the thermal insulation level, a relative heating capacity of 100 to $150 \mathrm{~W} / \mathrm{m}^{2}$ is estimated (https://www.haustechnikdialog.de/SHKwissen/1410/Spezifische-Heizlast). This leads to absolute heating capacity requirements of typically 5 to $8 \mathrm{~kW}$ for heating system in new buildings including sanitary hot water needs and of 10 to $15 \mathrm{~kW}$ for heating systems in existing buildings including sanitary hot water needs.

As an example, for Germany, the quantity of new buildings compared to the renovation buildings is just about one third (31\% in 2019) as per figure 1 . 


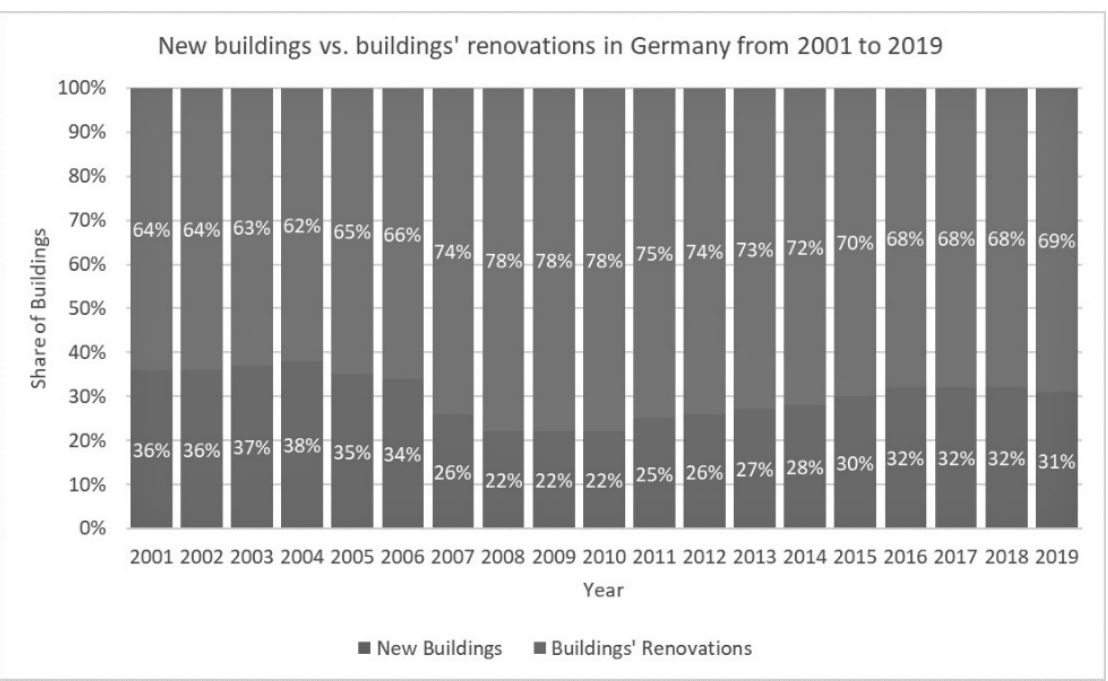

Figure 1: New versus renovation buildings in Germany from 2001 to 2019 (Breitkopf, 2020[1]).

\subsection{Temperature Levels Needs}

For residential applications / new buildings, the heat pump is operating at $35{ }^{\circ} \mathrm{C}$ for underfloor heating and $60{ }^{\circ} \mathrm{C}$ for sanitary hot water. For the renovation of buildings higher temperatures are needed to replace oil or gas boilers with $55^{\circ} \mathrm{C}$ for radiator heating and $60{ }^{\circ} \mathrm{C}$ for sanitary hot water. The target is to provide monovalent solutions to avoid a drop in efficiency due to usage of direct electrical heaters and to avoid an increase in $\mathrm{CO}_{2}$ emissions due to the adoption of additional gas boiler at low outside temperatures. This requires a high temperature lift at low environmental temperatures, e.g. $-25^{\circ} \mathrm{C}$ to $+60{ }^{\circ} \mathrm{C}$.

This high temperature lift requirement cannot be provided by all refrigerants.

\section{PERFORMANCE COMPARISION OF REFRIGERANTS}

A calculation tool has been developed to compare the performance of different refrigerants for Heat Pump applications. The calculation tool, developed in Excel ${ }^{\circledR}$, uses Refprop 10.0 (Reference Fluid Thermodynamic and Transport Properties) for the fluid properties. It is based on the basic thermodynamic equations linking pressure, temperature, enthalpy, and entropy to determine the capacity and coefficient of performance (COP) of a thermodynamic cycle.

\subsection{Comparison of R-410A, R-454B, R-452B, R-454C and R-32}

Figure 2 shows the capacity calculation results from the mentioned tool for the same compressor displacement. Except for R-454C the capacities are close to R-410A. For R-454C a bigger compressor would be required to achieve the same heating capacity, compared to R410A. 


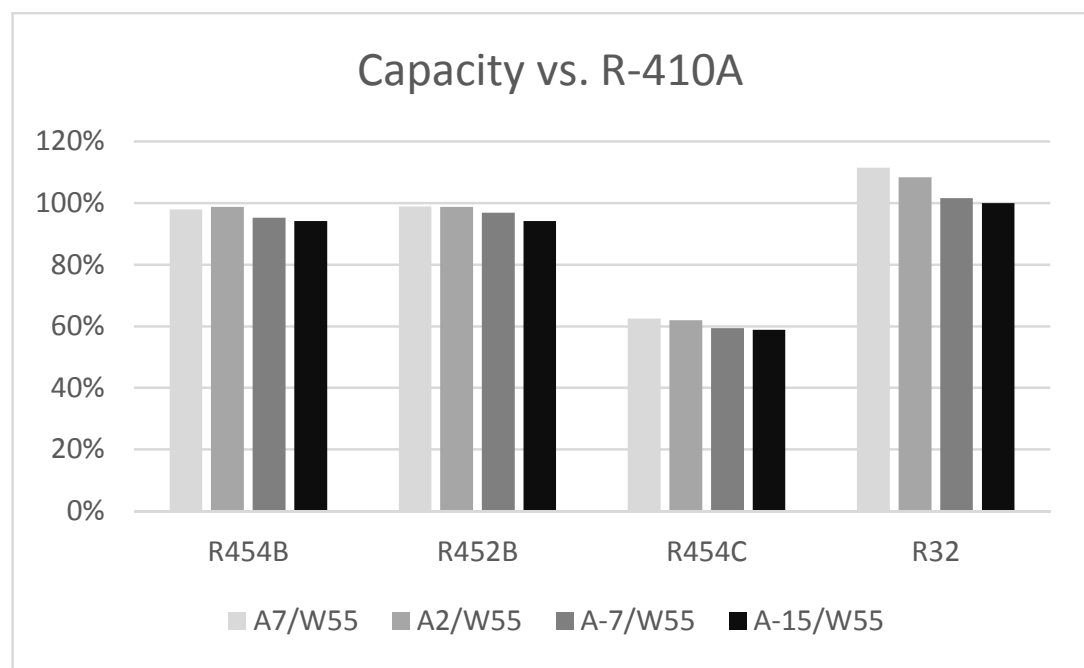

Figure 2: Heating capacity of different refrigerants at $\mathrm{A} / \mathrm{W}$ conditions for renovation buildings (W55)

Figure 3 shows the COP calculation results from the mentioned tool. For R-454B and R452B the COP at higher ambient temperature is above that of R-410A, while at lower ambient temperatures it is slightly below that of R-410A. For R-32 the COP drops considerably from high ambient temperature conditions to lower ambient temperatures. The only refrigerant performing above the values of R-410A for all operating conditions is R-454C which is also the one offering the lowest GWP (148).

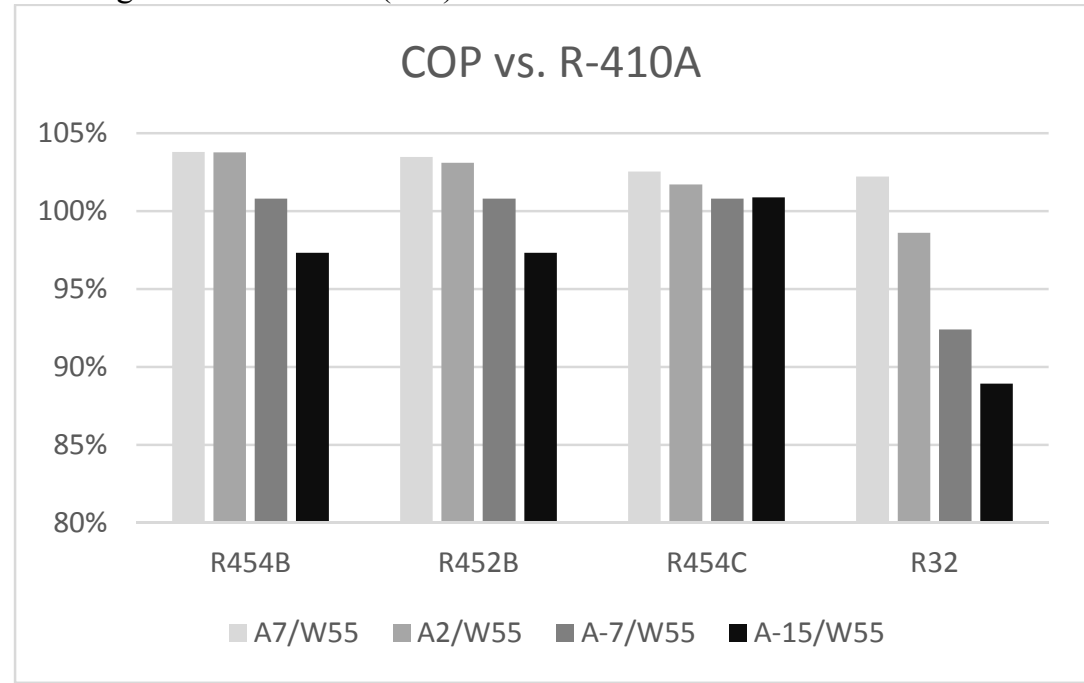

Figure 3: COP of different refrigerants at $\mathrm{A} / \mathrm{W}$ conditions for renovation buildings (W55)

Drop-in tests performed on A/W (R-410A) and B/W (R-407C) Heat Pumps by Fraunhofer ISE Institute $[6,7]$ show that just changing refrigerants without any modification to the heat pump system generally does not lead to an improvement. At some operating conditions, the drop-in refrigerant(s) performed better than the original ones and in some other the performance worsened. Similar results were shown by Hughes et. al. (2019) [9].

The discrepancies between performance calculations and test results from drop-in tests have been reported by Küpper et. al. (2021) [11]. 


\subsection{Operating range of $R-410 A, R-454 B, R-452 B, R-454 C$ and $R-32$ (compressor envelopes)}

R-410A can be referenced as today standard reference for Heat Pump applications. With dedicated technologies like enhanced vapor injection or enhanced liquid injection (EVI / $\mathrm{ELI})$ it is possible to cover the requested temperature lift in the range of $-25^{\circ} \mathrm{C}$ to $+60{ }^{\circ} \mathrm{C}$. This is sufficient for new buildings requiring $35^{\circ} \mathrm{C}$ water temperature for underfloor heating and $60{ }^{\circ} \mathrm{C}$ for sanitary hot water. At lower ambient temperatures EVI or ELI technology is strictly requested to achieve the high flow temperature. Without these technologies, $40{ }^{\circ} \mathrm{C}$ to $45{ }^{\circ} \mathrm{C}$ temperatures could only be achievable. Unfortunately, the COP will usually not increase during and due to EVI operation. For buildings renovation at average and cold European climate conditions, an additional electrical heater or parallel gas boiler would be necessary to reach the heating capacity and temperature requirements.

The behavior of R-454B and R-452B is very similar to that of R-410A and the requested compressor technology is also similar, if not the same.

With R-32 high flow temperatures can be achieved, but due to the very high discharge temperature, the maximum requested temperature lift $\left(-25^{\circ} \mathrm{C}\right.$ to $\left.+60{ }^{\circ} \mathrm{C}\right)$ cannot be achieved without protective measures preventing compressor over-heating. This protection is usually detrimental to both capacity and efficiency.

R-454C can be operated with standard one-stage compressors without EVI or ELI technologies, while achieving flow temperatures of up to $75^{\circ} \mathrm{C}$, even at very low ambient temperatures (as illustrated at chapter 5.2.). This is very beneficial for the application in buildings renovation, as often the existing hydronic system of radiators requests rather high flow temperatures. For sanitary hot water production, the additional legionella controls are not necessary anymore as a condensing temperature of $+60{ }^{\circ} \mathrm{C}$ can still be achieved directly at $-30{ }^{\circ} \mathrm{C}$ ambient temperature.

\section{EMISSIONS IMPACT IN VARIOUS COUNTRIES}

Although there is no combustion in a vapor compression cycle Heat Pumps, there can be direct emissions caused by leaking refrigerant with certain GWP from the system. Indirect emissions are always given due to the electrical power consumption of the Heat Pump. Both sources of emissions are further investigated in the following chapter.

\subsection{Leak rate of Heat Pumps (direct emissions)}

Direct emissions of Heat Pumps can be caused by refrigerant leaking from the Heat Pump system. The decisive factor here is the GWP of the refrigerant and the refrigerant leakage rate.

It was determined from analysis of F-gas logbooks in March 2014 that annual leakage rates from Heat Pumps were of the order of $3.8 \%$ for non-domestic applications and $3.5 \%$ for domestic applications (Eunomia, 2014) [2].

Based on this annual leakage rate of $3.5 \%$, the direct emissions over the whole life cycle time (assuming e.g. 10 years) can be calculated for each refrigerant (equal to $35 \%$ of the initial refrigerant charge). We will investigate the emissions for R-410A (GWP 2088), representing a standard reference, and for R-454C (GWP 148) representing a long-term solution. Heat Pumps with 5 to $10 \mathrm{~kW}$ heating capacity, which represent about $60 \%$ of the installed market, the refrigerant charge can be estimated to 1.8 to $2 \mathrm{~kg}$. For Heat Pumps of 10 to 20 $\mathrm{kW}$ heating capacity, which represent about $30 \%$ of the installed market, the refrigerant charge can be estimated to 2.5 to $3 \mathrm{~kg}$. As a worst-case scenario, the highest values were 
considered. The lower capacity range ( 5 to $10 \mathrm{~kW}$ ) is representative of new buildings applications, while the higher capacity $(10$ to $20 \mathrm{~kW})$ represents buildings renovation applications. The direct emissions over 10 years life cycle time are shown in table 1 .

Table 1: 10 years direct emissions of two refrigerants for two different charge sizes

\begin{tabular}{|l|c|c|c|c|}
\hline Refrigerant & \multicolumn{2}{|c|}{ R-410A } & \multicolumn{2}{c|}{ R-454C } \\
\hline GWP (AR4) & \multicolumn{2}{|c|}{2088} & 2 & 3 \\
\hline Charge (kg) & 2 & 3 & $3.5 \%$ & $3.5 \%$ \\
\hline annual leakage rate (\%) & $3.5 \%$ & $3.5 \%$ & 0.10 & 0.15 \\
\hline $\begin{array}{l}10 \text { years Direct emissions } \\
\left(\mathrm{TCO} \mathrm{O}_{2} \mathrm{e}\right)\end{array}$ & 1.46 & 2.19 & & \\
\hline
\end{tabular}

\subsection{Emission Factor in EU Countries (indirect emissions)}

Indirect emissions from Heat Pumps are generated by the process of generating electrical power requested to make the Heat Pump operating. Here, the kind of power generation and the efficiency of this process determines the resulting emission factor of electrical power generation.

The European Environment Agency (EEA) has published the evolution of emission factor or $\mathrm{CO}_{2}$ emission intensity for EU countries until 2016 as shown in figure 4 [5].

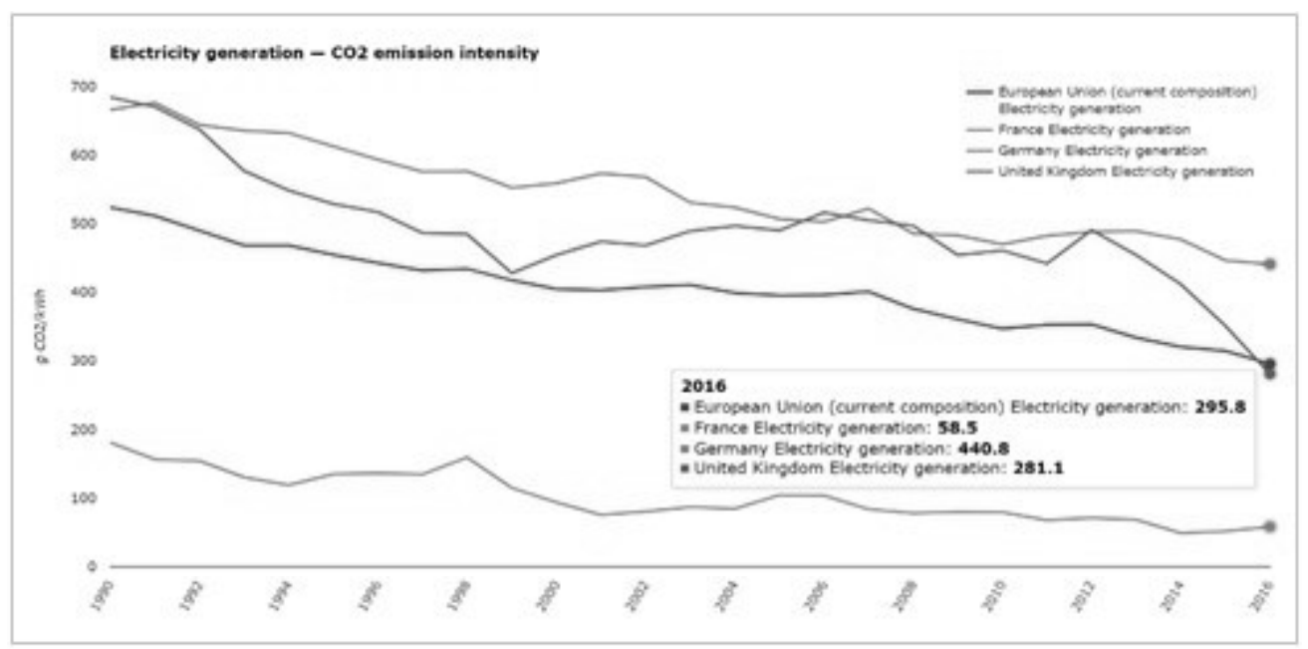

Figure 4: Evolution of emission factor or $\mathrm{CO} 2$ emission intensity for some EU countries (EEA)

Also published by EEA [5], figure 5 shows a breakdown by country and the average value for $27 \mathrm{EU}$ countries in 2018 to be about $300 \mathrm{gCO}_{2} / \mathrm{kWh}$. 


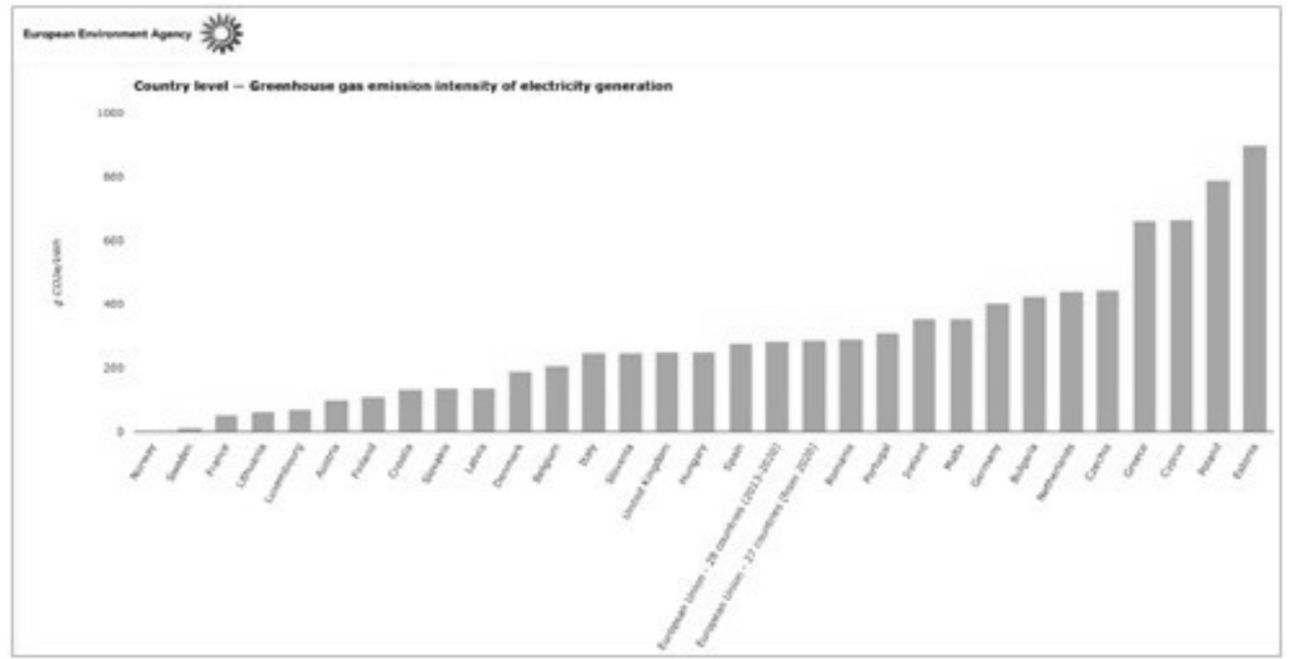

Figure 5: Emission factor or CO2 emission intensity for EU countries in 2018 (EEA)

For an average Central-Europe single-family house of $140 \mathrm{~m}^{2}$ surface we investigated two cases: a new building with a heat capacity requirement of $35 \mathrm{~W} / \mathrm{m}^{2}$, resulting in 5.000 $\mathrm{kWh} /$ year total heating energy consumption and a renovation building with a heat capacity requirement of $140 \mathrm{~W} / \mathrm{m}^{2}$, resulting in $20.000 \mathrm{kWh} /$ year total heating energy consumption. Presuming an average $\mathrm{CO}_{2}$ emission factor of $0,3 \mathrm{kgCO}_{2} \mathrm{e} / \mathrm{kWh}$ the new building would emit 1,5 $\mathrm{TCO}_{2} \mathrm{e} /$ year and the renovated building would emit $6,0 \mathrm{TCO}_{2} \mathrm{e} /$ year. During the whole life cycle time of 10 years the emissions would sum up to $15 \mathrm{~T} \mathrm{CO}_{2} \mathrm{e}$ for a new building and to $60 \mathrm{~T} \mathrm{CO}_{2} \mathrm{e}$ for a renovation building.

\subsection{Total Emissions}

The total emissions sum up from direct emissions due to refrigerant leakage and from indirect emissions caused by production of electrical energy as shown in figures 6 and 7 , calculated with a SCOP of 3,5 .

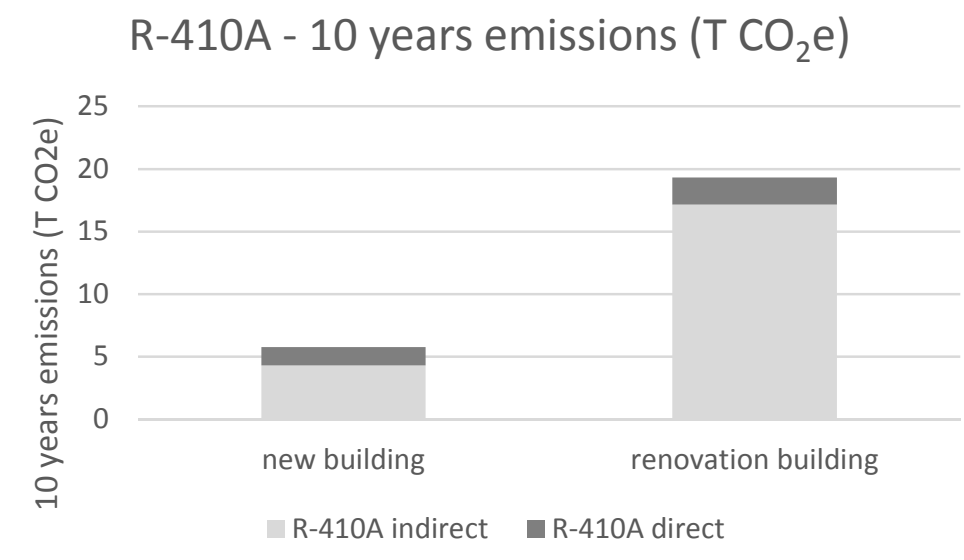

Figure 6: 10 years emission with R-410A in new and renovation building 


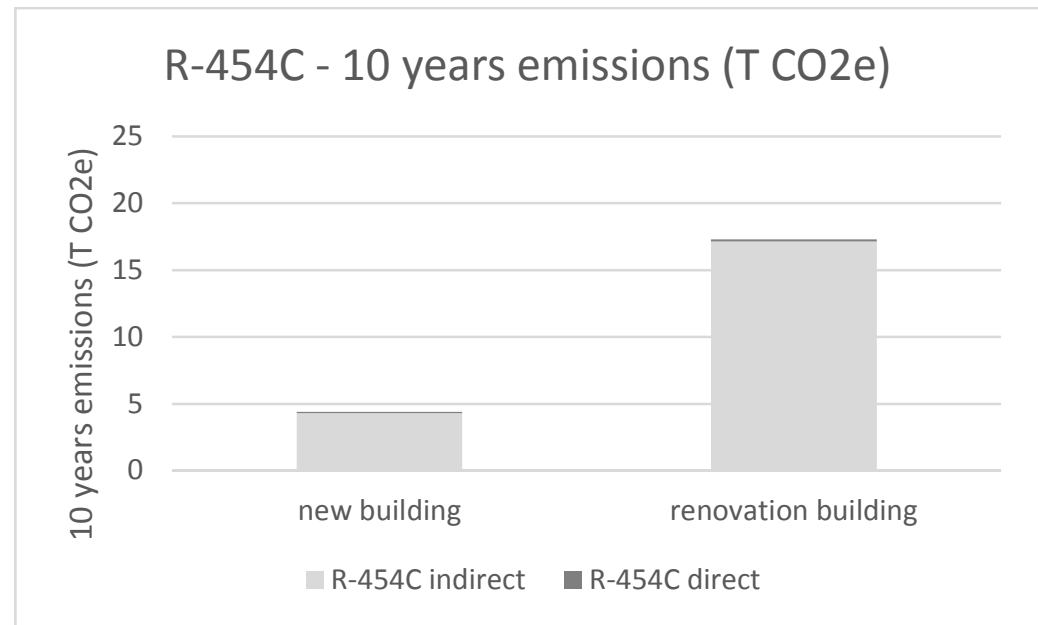

Figure 7: 10 years emission with R-454C in new and renovation building

Emissions are caused in vast majority by indirect emissions originated by the energy consumption of the system. The ratios of direct emissions compared to indirect emissions are shown in figure 8 . While for R-410A the GWP value causes still $34 \%$ of emissions for new buildings and $12.8 \%$ for renovation buildings the GWP value of R-454C does not bring a relevant contribution in terms of emissions, causing just $2,3 \%$ respectively $0,9 \%$ of emissions.

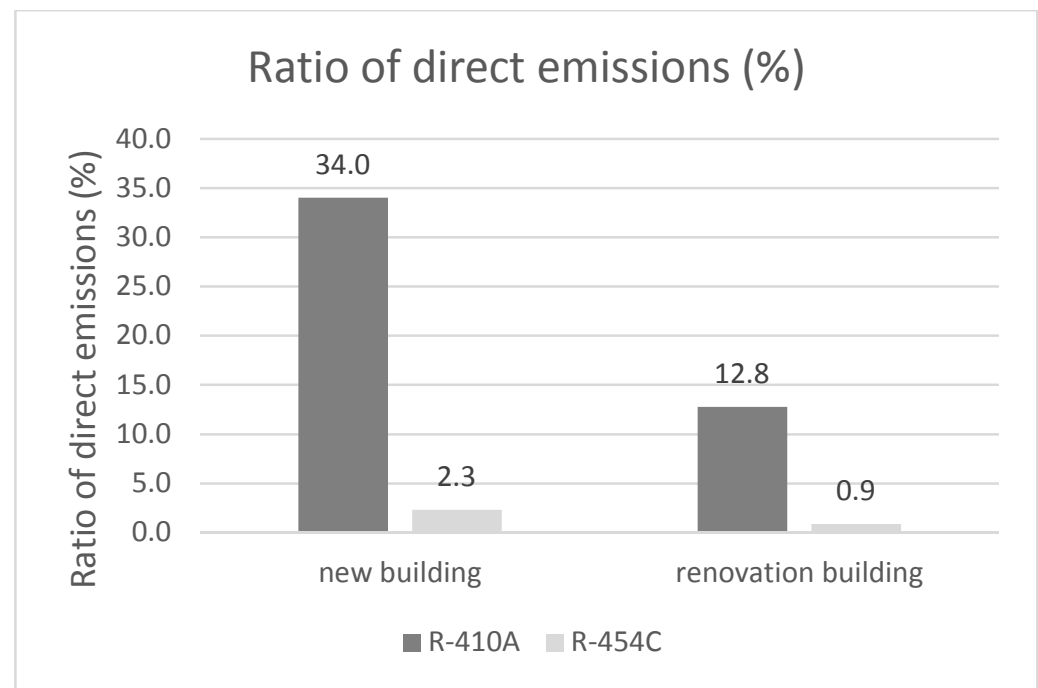

Figure 8: Ratio of direct emissions relative to indirect emissions

It is to be considered that the leakage rate of $3.5 \%$ - estimated in 2014 - does not reflect today state of the art. More realistic leakage rates should be in the range of $0,25 \% /$ year, reflecting a leakage of $5 \mathrm{~g}$ /year. With this estimation the ratio of direct emissions would be in the range of $0,1 \%$ for renovation buildings and below $0,3 \%$ for new buildings.

This shows that the efficiency of Heat Pump systems is by far the major parameter affecting total system-emissions. 


\section{WAYS FOR REACHING THE THEORETICAL EFFICIENCIES}

Several theoretical calculations, comparing the performance of different refrigerant solutions, have shown that there is a huge potential for improving system efficiency with low GWP A2L refrigerants. Several drop-in tests with the same refrigerants have shown that the theoretical calculated efficiencies cannot easily be achieved by dropping the high-performance refrigerant into an existing Heat Pump system. The conclusion is very clear: The heat pump system should be designed "around the refrigerant"!

As many low GWP A2L refrigerant blends are zeotropic mixtures, they present a temperature glide which must be considered when designing and sizing heat exchangers (evaporators and condensers). This is not a novelty, but has it been addressed successfully e.g. when using R$407 \mathrm{C}$ ? Ignoring this refrigerant behavior would lead to non-optimal solutions. For evaporators this can be used in a beneficial way to increase capacity and efficiency. To obtain the same performance, condensers must be dimensioned differently, with a slightly bigger size compared to those adapted to azeotropic refrigerants.

When operating with zeotropic refrigerant blends, the implementation of dedicated refrigerant circuit design might be beneficial for increasing system capacity and efficiency.

Using a compressor which has been designed for a "similar" refrigerant, but not optimized for low GWP A2L refrigerants will work in general in a new system, but the maximum performance - capacity and efficiency wise - will not be achieved. A dedicated compressor shall be used to enable maximum system efficiency.

There are several examples of existing compressors in the market showing that the performance and the operating temperature range strongly depend on the choice and design of the compressor.

\section{CONCLUSIONS}

Building's renovation requires an extended operating temperature range compared to new buildings. This is due to the existing hydronic system consisting of heating radiators requiring higher water flow temperature to provide the heating capacity needs. Due to often missing or less efficient thermal insulation of old buildings, usually the required heating capacity is higher as well.

With existing refrigerant technologies - namely R-410A - these needs cannot be satisfied across the entire year, as at very low ambient temperatures, additional electrical heaters in the buffer tank or separate oil or gas boilers can provide the necessary heating capacity. Both solutions are characterized by much lower efficiency and contribute to much higher system emissions at those conditions.

With the low GWP (148) refrigerant R-454C, the system efficiency can be improved compared to R-410A over the whole operating range and all temperature conditions. In addition, a flow temperature of $75^{\circ} \mathrm{C}$ can be easily achieved without additional technical complications, like vapor or liquid injection. This way, the system cost can also be reduced.

It has been shown that the direct emissions contribution from R-454C represents less than 1 $\%$ of total emissions over the complete lifetime of a Heat Pump. This leads to the conclusion that system efficiency is the main parameter influencing system emissions through its contribution to reducing the operational power consumption. 


\section{REFERENCES}

1. Breitkopf, Wohnungsbau - Struktur nach Art der Bauleistung in Deutschland bis 2019, 08.12.2020, Statista.com

2. Eunomia Research \& Consulting Ltd and the Centre for Air Conditioning and Refrigeration Research (London Southbank University), Impacts of Leakage from Refrigerants in Heat Pumps, https://assets.publishing.service.gov.uk/government/uploads/system/uploads/attachment_data/file/303689/Eunomia_-_DECC_Refrigerants_in_Heat_Pumps_Final_Report.pdf; March 2014

3. European Commission: Annexes to the Commission Recommendation on the content of the comprehensive assessment of the potential for efficient heating and cooling under Article 14 of Directive 2012/27/EU, C(2019) 6625 final, ANNEXES 1 to 7, Brussels, 25.9.2019.

4. European Commission: Communication from the Commission to the European Economic and Social Committee and the Committee of the Regions, A Renovation Wave for Europe - greening our buildings, creating jobs, improving lives, $\operatorname{COM}(2020) 662$ final, Brussels, 14.10.2020.

5. European Environment Agency (EEA) Report "The European environment - state and outlook 2020”; ISBN 978-92-9480-090-9; 2019

6. Fraunhofer Institute for solar energy systems ISE: "Test of an air-to-water heat pump with four refrigerants"; Test Report No. B-HPC-19-0316-1; 2020

7. Fraunhofer Institute for solar energy systems ISE: "Measurement of a brine-to-water heat pump with four refrigerants"; Test Report No. B-HPC-19-0316-2; 2020

8. Harvey, Simon: The role of heat pumps for decarbonization of industrial processes, $12^{\text {th }}$ IEA Heat Pump Conference 2017, Rotterdam

9. Hughes, Joshua \& Juhasz, Jason: "Low GWP Refrigerant Solutions for Heat Pumps", January 12, 2019

10. Harvey, Simon: The role of heat pumps for decarbonization of industrial processes, $12^{\text {th }}$ IEA Heat Pump Conference 2017, Rotterdam

11. Küpper, Hans-Dieter; Chereau, Loic; Saab, Samer: Energy efficiency, Safety and Sustainability of A2L low GWP HFO based refrigerant solutions in Heat Pump Applications; HFO2021 2nd IIR Conference on HFOs and Low GWP blends, Japan, $16^{\text {th }}-18^{\text {th }}$ June 2021

12. Nowak, Thomas (EHPA): Heat Pumps; Integrating technologies to decarbonize heating and cooling, European Copper Institute, Autumn 2018.

13. Ries: Highly Rotary Compressors, RIES GmbH, D 64569 Nauheim, GERMANY, Product Catalogue 10/2020

14. Timm, Edgar, ETSuS UG, Assessment: "2020 European Residential Heat Pump Market Outline Under Implication of Revised IEC 60335-2-40”; 2020 